\title{
Kontribusi Kesenian Jaranan Turonggo Yakso sebagai Sumber Belajar Ilmu Pengetahuan Sosial (Suatu Kajian Etnografi)
}

\author{
Roki’ Amrullah ${ }^{1}$, Mohammad Zainuddin ${ }^{2}$, Sri Untari ${ }^{3}$ \\ ${ }^{1}$ Pendidikan Dasar-Universitas Negeri Malang \\ ${ }^{2}$ Keguruan Sekolah Dasar dan Prasekolah-Universitas Negeri Malang \\ ${ }^{3}$ Pendidikan Kewarganegaraan-Universitas Negeri Malang
}

\begin{tabular}{l}
\hline INFO ARTIKEL \\
\hline Riwayat Artikel: \\
Diterima: $15-05-2020$ \\
Disetujui: $21-12-2020$ \\
\hline
\end{tabular}

\section{Kata kunci:}

jaranan turonggo yakso of art; social sciences; ethnographic studies; kesenian jaranan turonggo yakso; ilmu pengetahuan sosial; kajian etnografi

\begin{tabular}{l} 
Alamat Korespondensi: \\
Roki’ Amrullah \\
Pendidikan Dasar \\
Universitas Negeri Malang \\
Jalan Semarang 5 Malang \\
E-mail: rockyoungest@gmail.com \\
\hline \hline
\end{tabular}

\section{ABSTRAK}

Abstract: The focus of this research is (1) analyzing Jaranan Turonggo Yakso Arts based on the social science concept point of view, (2) adjusting Jaranan Turonggo Yakso Arts with basic IV social competence class IV, and (3) making a map of Jaranan Turonggo Yakso Art competence as a source of social studies learning class IV. This research procedure uses Spradley's ethnographic approach. Jararan Turonggo Yakso art is in accordance with the importance of the topic of the material on the competence of student achievement.

\begin{abstract}
Abstrak: Fokus penelitian ini yaitu (1) menganalisis Kesenian Jaranan Turonggo Yakso berdasarkan sudut pandang konsep ilmu sosial, (2) menyesuaikan Kesenian Jaranan Turonggo Yakso dengan kompetensi dasar IPS kelas IV, dan (3) membuat peta kompetensi Kesenian Jaranan Turonggo Yakso sebagai sumber belajar IPS kelas IV. Prosedur penelitian ini menggunakan pendekatan etnografi milik Spradley. Kesenian Jararan Turonggo Yakso sesuai dengan kepentingan topik materi pada kompetensi capaian peserta didik.
\end{abstract}

Budaya berpartisipasi dalam pendidikan dasar, budaya memengaruhi persepsi, sikap, dan perilaku kelas peserta didik (Hvitfeldt, 1986). Seni tradisional merupakan identitas budaya dari sebuah komunitas manusia, yang memiliki peran spesifik secara sosial dan ritual sebagai fasilitator untuk harapan dan doa mereka (Irianto, 2017). Kesenian adalah topik yang unik dalam model dan strategi belajar ketika diintegrasikan ke dalam pembelajaran (Lee \& Cawthon, 2015). Kesenian sebagai salah satu budaya tradisional menjadi salah satu faktor yang secara positif memengaruhi kinerja akademis anak-anak sekolah dasar, enkulturasi secara langsung terkait dengan keberhasilan sekolah (Whitbeck et al., 2020).

Kesenian Jaranan Turonggo Yakso berawal dari upacara Baritan (bubar ngarit tanduran) atau setelah panen, bertujuan untuk mensyukuri hasil panen dengan cara membagikan kepada bumi dan saling berbagi kepada yang membutuhkan (Widyanto Kurniadi, \& Wahida, 2019b). Ciri khas Turonggo Yakso dilihat dari bentuk eblek bagian atas tubuh berwujud raksasa dan bagian bawah tubuh berwujud kuda (Perkasa \& Prasetyo, 2018). Peran penari Turonggo Yakso terbagi menjadi pemain Barongan, Celeng, dan penari penunggang kuda berkepala raksasa (Wisang, 2019).

Kesenian tradisional seperti Turonggo Yakso dapat diintegrasikan ke dalam pembelajaran dikarenakan memiliki materi berdasarkan peristiwa yang mengajarkan nilai kehidupan (Alaz, Suryani, \& Djono, 2018). Turonggo Yakso adalah kajian sejarah yang dianggap bisa diintegrasikan untuk sumber belajar ilmu pengetahuan sosial. Sumber belajar sendiri itu dapat diidentifikasikan sebagai pesan, orang, data, fakta, ide, benda, teknik, dan latar yang dapat menimbulkan kegiatan belajar (Abdullah, 2012). Turonggo Yakso berpotensi menjadi sumber belajar bagi ilmu pengetahuan sosial.

Ilmu pengetahuan sosial memiliki ruang lingkup dan karakter program studi sosial yang sangat bervariasi. Ilmu pengetahuan sosial didefinisikan sebagai sejumlah konsep disiplin ilmu sosial, seperti sejarah, geografi, psikologi, ekonomi, sosiologi, antropologi, dan ekonomi yang dipadukan dan disederhanakan untuk kepentingan pembelajaran (Nelson, 2001). Ilmu sosial disederhanakan untuk tujuan pedagogik yang berarti memberikan pengetahuan, pemahaman, dan kemampuan analisis terhadap kondisi sosial masyarakat yang dinamis kepada peserta didik (Tryon, 1983). 
Penelitian ini didasarkan pada belajar kontekstual yaitu ketika peserta didik belajar cenderung mengungkapkan pengetahuan dan keterampilan dari konteks pengalaman yang dekat kehidupan nyatanya karena pengetahuan tidak dapat dipisahkan dari konteks dan kegiatan dimana peserta didik berkembang. (Sears, 2003). Salah satu ciri-ciri adanya belajar kontekstual yaitu terdapat koneksi peserta didik dengan konteks dunia nyata (Glynn \& Winter, 2004). Maka peneliti menganalisis Turonggo Yakso agar menjadi sumber belajar kontekstual bagi IPS untuk melengkapi sumber belajar yang masih menggunakan konteks jauh dari pengalaman peserta didik. Maka tujuan penelitian ini, yaitu (1) untuk mengetahui jaranan Turonggo Yakso dari sudut pandang ilmu pengetahuan sosial, (2) untuk mengetahui kesesuaian kesenian jaranan turonggo yakso dengan kompetensi dasar ilmu pengetahuan sosial kelas IV, dan (3) untuk mengetahui peta kompetensi kesenian jaranan turonggo yakso sebagai sumber belajar ilmu pengetahuan sosial kelas IV. Secara singkat penelitian Turonggo Yakso mengandung konsep-konsep ilmu sosial yang dapat berkontribusi untuk mendukung proses belajar ilmu pengetahuan sosial.

\section{METODE}

\section{Desain Penelitian}

Pendekatan yang dipilih adalah pendekatan etnografi dengan mendeskripsikan atas suatu kebudayaan untuk memahami suatu pandangan hidup dari sudut pandang penduduk asli (Spradley, 1997). Penelitian etnografi sebagai deskripsi atas suatu kebudayaan, untuk memahami suatu pandangan hidup dari sudut pandang penduduk asli. Penelitian ini dilakukan di Kecamatan Dongko yang seluruh wilayahnya hampir merupakan daerah perbukitan serta sedikit daerah dataran rendahnya. Wilayahnya memiliki persediaan sumber air di dekat permukiman masyarakat. Mata pencaharian masyarakat Dongko bersumber dari dunia agraris, seperti persawahan, perkebunan, ladang, dan hutan (Surur, 2013).

\section{Pengumpulan Data}

Pengumpulan data pada penelitian ini menggunakan wawancara mendalam yang bertujuan untuk mengeksplorasi pandangan, pengalaman yang lebih dalam memahami fenomena serta kedalaman informasi yang diperlukan (Gill, Stewart, Treasure, \& Chadwick, 2008). Produksi hasil wawancara perlu dilakukan secara sengaja atau sadar dan berulang untuk mendapatkan kedalaman informasi yang diperlukan. Berikut sumber informasi yang diperoleh dari wawancara (Tabel 1).

Tabel 1. Sumber Informasi

\begin{tabular}{lll}
\hline No & Data diperoleh melalui wawancara & \multicolumn{1}{c}{ Sumber Informasi } \\
\hline 1 & Sejarah, asal-usul, gerakan jaranan & Pamrihanto (sesepuh Dongko) \\
2 & Peralatan jaranan & Mu'an (sesepuh Dongko) \\
3 & Asal-usul jaranan & Yeni Wulandari (guru SD) \\
4 & Sejarah jaranan & Joko Purwitno (dinas pariwisata dan kebudayaan) \\
\hline
\end{tabular}

Berdasarkan tabel 1, dapat disimpulkan bahwa ada empat informan yang diwawancarai untuk memperoleh data-data tersebut. Peneliti juga mengumpulkan sumber data penelitian menggunakan pengamatan dan dokumentasi untuk memudahkan proses analitik (Polkinghorne, 2005). Penelitian etnografi memerlukan kekayaan data untuk memastikan hasil yang valid (Easton et al., 2000). Dengan demikian, ketiga prosedur pengumpulan data perlu dilakukan untuk menghasilkan keluasan serta kedalaman informasi yang diperlukan peneliti (Polkinghorne, 2005).

\section{Analisis Data}

Analisis data pada penelitian ini menggunakan metode etnografi milik Spradley. Analisis data metode etnografi dilakukan selama proses penelitian (Moleong, 2013). Peneliti memilih salah satu analisis pada metode etnografi yaitu analisis komponen. Analisis komponen bertujuan untuk memperoleh atribut atau komponen.

Rancangan penelitian berdasarkan metode etnografi, meliputi (1) memilih domain berdasarkan hubungan semantik seperti hubungan spasial, sebab-akibat, rasional, lokasi, fungsi, alat-tujuan, urutan, dan memberi atribut, (2) identifikasi dimensi dilakukan dengan mengidentifikasi suatu ide atau konsep, (3) menggabung dimensi dilakukan dengan menggabungkan suatu ide atau konsep yang sangat terkait maknanya, (4) menyiapkan pertanyaan untuk mengumpulkan jenis-jenis informasi yang dibutuhkan dari informan, (5) melakukan wawancara untuk memperoleh data yang diperlukan, (6) melakukan analisis terhadap informasi yang diperoleh dari informan, dan (7) menulis laporan penelitian sesuai panduan penulisan.

\section{HASIL}

\section{Analisis Kesenian Jaranan Turonggo Yakso dari Sudut Pandang IPS}

Hasil analisis menunjukkan Kesenian Jaranan Turonggo Yakso dikaji melalui sudut pandang sejumlah konsep ilmu sosial. Dari sudut pandang sejarah, Turonggo Yakso mengajarkan pengalaman hidup masyarakat Dongko berdasarkan kurun waktu masa lampau. Sudut pandang politik, mengajarkan usaha menegakkan norma dan nilai yang ditempuh masyarakat Dongko untuk mewujudkan kebaikan masyarakat agraris. Sudut pandang psikologi, mengajarkan pemikiran dan tindakan masyarakat Dongko dalam melawan angkara murka. Sudut pandang geografi, mengajarkan karakteristik wilayah Dongko yang 
merupakan daerah dataran tinggi dengan potensi agrarisnya. Sudut pandang antropologi, mengajarkan cara hidup masyarakat Dongko dalam bersosial, berbudaya, dan beragama. Sudut pandang sosiologi, mengajarkan interaksi kelompok paguyuban masyarakat Dongko. Terakhir dari sudut pandang ekonomi, mengajarkan kegiatan ekonomi masyarakat Dongko yaitu memproduksi bahan baku pangan di sektor pertanian. Walaupun dalam kajian llmu sosial terpisah-pisah, apabila untuk kepentingan ilmu pengetahuan sosial maka tetap dipadukan dan disederhanakan untuk kepentingan pembelajaran.

\section{Analisis Kesesuaian Kesenian Jaranan Turonggo Yakso dengan Kompetensi Dasar IPS kelas IV}

Agar Kesenian Jaranan Turonggo Yakso menjadi sumber belajar IPS maka perlu disesuaikan dengan kompetensi dasar. Penelitian menyesuaikan dengan kompetensi dasar 3.2 dan 4.2 dengan tema "Indahnya Kebersamaan". Isi dari kompetensi dasar yaitu " 3.2. Mengidentifikasi keragaman sosial, ekonomi, budaya, etnis, dan agama di provinsi setempat sebagai identitas bangsa Indonesia; serta hubungannya dengan karakteristik ruang” dan " 4.2. Menyajikan hasil identifikasi mengenai keragaman sosial, ekonomi, budaya, etnis, dan agama di provinsi setempat sebagai identitas bangsa Indonesia; serta hubungannya dengan karakteristik ruang". Penyesuaian dengan kompetensi dasar dilakukan melalui analisis topik kompetensi dasar, setting, konten, dan organisasi materi. Pernyataan tersebut dijelaskan pada tabel 2.

Tabel 2. Kesesuaian Turonggo Yakso dengan Kompetensi Dasar

\begin{tabular}{|c|c|c|c|c|c|c|}
\hline \multirow[b]{2}{*}{ No } & \multirow{2}{*}{$\begin{array}{c}\text { Topik } \\
\text { Kompetensi } \\
\text { Dasar }\end{array}$} & \multirow{2}{*}{$\begin{array}{l}\text { Konsep Ilmu } \\
\text { Sosial }\end{array}$} & \multicolumn{3}{|c|}{ Konten } & \multirow[b]{2}{*}{ Organisasi Materi } \\
\hline & & & Fakta & Konsep & Generalisasi & \\
\hline 1 & Keragaman sosial & $\begin{array}{l}\text { Konsep ilmu } \\
\text { sosiologi }\end{array}$ & $\begin{array}{l}\text { Masyarakat di Dongko } \\
\text { hidup bersama dan sering } \\
\text { bergotong royong }\end{array}$ & $\begin{array}{l}\text { Kelompok } \\
\text { sosial }\end{array}$ & $\begin{array}{l}\text { Kelompok sosial } \\
\text { paguyuban } \\
\text { dipengaruhi } \\
\text { kebersamaan hidup }\end{array}$ & $\begin{array}{l}\text { Interaksi sosial } \\
\text { kehidupan } \\
\text { masyarakat }\end{array}$ \\
\hline 2 & $\begin{array}{l}\text { Keragaman } \\
\text { ekonomi }\end{array}$ & $\begin{array}{l}\text { Konsep ilmu } \\
\text { ekonomi }\end{array}$ & $\begin{array}{l}\text { Masyarakat pertanian } \\
\text { menyiapkan hasil panen } \\
\text { untuk konsumsi } \\
\text { masyarakat }\end{array}$ & Produksi & $\begin{array}{l}\text { Produksi adalah } \\
\text { kegiatan } \\
\text { menyediakan barang }\end{array}$ & $\begin{array}{l}\text { Kehidupan } \\
\text { perekonomian } \\
\text { Masyarakat }\end{array}$ \\
\hline 3 & $\begin{array}{l}\text { Keragaman } \\
\text { budaya }\end{array}$ & $\begin{array}{l}\text { Konsep ilmu } \\
\text { antropologi }\end{array}$ & $\begin{array}{l}\text { Masyarakat di Dongko } \\
\text { memiliki kesenian khas } \\
\text { tari Turonggo Yakso }\end{array}$ & $\begin{array}{l}\text { Warna } \\
\text { kebudayaan } \\
\text { manusia }\end{array}$ & $\begin{array}{l}\text { Kebudayaan ditandai } \\
\text { dengan adanya hasil } \\
\text { karya manusia }\end{array}$ & $\begin{array}{l}\text { Kehidupan } \\
\text { masyarakat dan } \\
\text { kelembagaan } \\
\text { budaya }\end{array}$ \\
\hline 4 & Keragaman etnis & $\begin{array}{l}\text { Konsep ilmu } \\
\text { antropologi }\end{array}$ & $\begin{array}{l}\text { Masyarakat di Dongko } \\
\text { melaksakan upacara } \\
\text { tradisi setelah panen }\end{array}$ & $\begin{array}{l}\text { Kehidupan } \\
\text { masyarakat }\end{array}$ & $\begin{array}{l}\text { Kehidupan } \\
\text { masyarakat } \\
\text { dipengaruhi oleh } \\
\text { kesamaan perilaku }\end{array}$ & $\begin{array}{l}\text { Kehidupan } \\
\text { masyarakat dan } \\
\text { kelembagaan sosial }\end{array}$ \\
\hline 5 & $\begin{array}{l}\text { Keragaman } \\
\text { agama }\end{array}$ & $\begin{array}{l}\text { Konsep ilmu } \\
\text { antropologi }\end{array}$ & $\begin{array}{l}\text { Masyarakat di Dongko } \\
\text { sering berbagi hasil panen } \\
\text { sebagai rasa syukur } \\
\text { kepada Tuhan }\end{array}$ & $\begin{array}{l}\text { Kehidupan } \\
\text { masyarakat }\end{array}$ & $\begin{array}{l}\text { Kehidupan } \\
\text { masyarakat } \\
\text { dipengaruhi oleh } \\
\text { nilai keagamaan }\end{array}$ & $\begin{array}{l}\text { Kehidupan } \\
\text { masyarakat dan } \\
\text { kelembagaan agama }\end{array}$ \\
\hline 6 & $\begin{array}{l}\text { Karakteristik } \\
\text { ruang }\end{array}$ & $\begin{array}{l}\text { Konsep ilmu } \\
\text { geografi }\end{array}$ & $\begin{array}{l}\text { Masyarakat di dataran } \\
\text { tinggi banyak yang } \\
\text { berprofesi petani }\end{array}$ & Dataran tinggi & $\begin{array}{l}\text { Dataran tinggi } \\
\text { merupakan potensi } \\
\text { area pertanian }\end{array}$ & $\begin{array}{l}\text { Wilayah geografis } \\
\text { tempat tinggal } \\
\text { masyarakat }\end{array}$ \\
\hline
\end{tabular}

Berdasarkan tabel 2, hasil analisis menunjukkan Turonggo Yakso dapat disesuaikan dengan topik materi kompetensi dasar. Topik materi yang sesuai dengan Turonggo Yakso yaitu topik keragaman sosial, keragaman ekoomi, keragaman budaya, keragaman etnis, keragaman agama, dan karakteristik ruang. Turonggo Yakso bisa dipelajari melalui topik kompetensi dasar. Konsep ilmu sosial yang dipakai untuk mempelajari topik materi tersebut yaitu konsep ilmu sosiologi, ekonomi, antropologi, dan geografi.

Konsep-konsep ilmu sosial itu dipelajari melalui organisasi materi yang didapatkan. Organisasi materi untuk mempelajari konsep sosiologi yaitu interaksi sosial kehidupan masyarakat. Konsep ekonomi dipelajari dengan materi kehidupan perekonomian masyarakat dataran tinggi. Konsep antropologi dipelajari dengan materi kehidupan manusia dalam kelembagaan budaya, kelembagaan sosial, dan kelembagaan agama. Konsep geografi dipelajari dengan materi wilayah geografis tempat tinggal masyarakat.

\section{Peta Kompetensi Kesenian Jaranan Turonggo Yakso sebagai Sumber Belajar IPS}

Turonggo Yakso sebagai salah satu sumber belajar IPS kelas IV digambarkan melalui peta kompetensi. Sajian peta kompetensi untuk mempermudah dalam melihat kontribusi khasanah ilmu Turonggo Yakso untuk organisasi materi IPS kelas IV dijelaskan pada gambar 1 . 


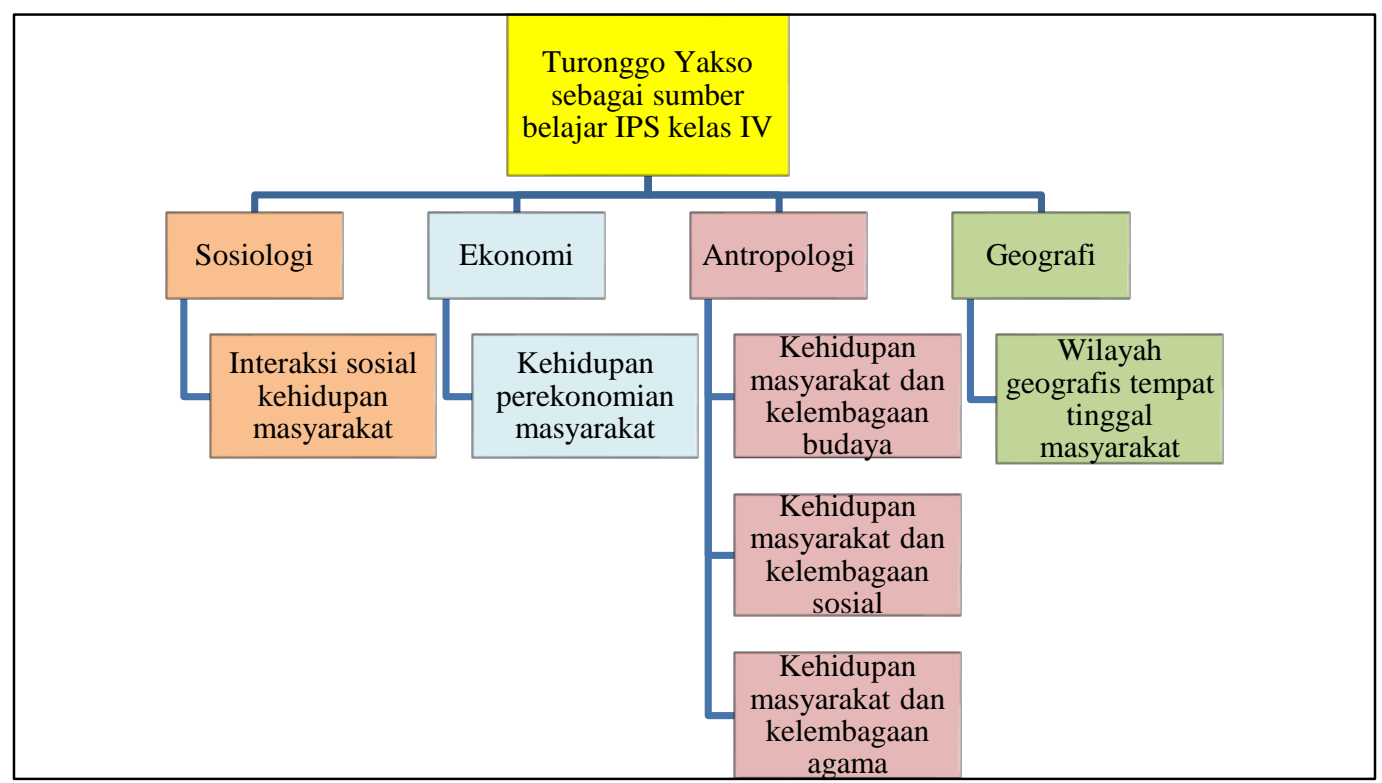

Gambar 1. Peta Kompetensi Turonggo Yakso sebagai Sumber Belajar IPS

Berdasarkan gambar 1, peta kompetensi menggambarkan kontribusi Turonggo Yakso untuk sumber belajar IPS kelas IV. Turonggo Yakso berkontribusi untuk konsep ilmu sosiologi, konsep ilmu ekonomi, konsep ilmu antropologi, dan konsep ilmu geografi. Empat konsep ilmu sosial yang dimiliki Turonggo Yakso digunakan untuk mempelajari topik keragaman sosial, keragaman ekonomi, keragaman budaya, keragaman etnis, keragaman agama, dan karakteristik ruang.

Turonggo Yakso berkontribusi untuk materi-materi yang dapat diajarkan kepada peserta didik melalui belajar tentang konsep ilmu sosiologi, ekonomi, antropologi, dan geografi. Organisasi materi untuk mempelajari konsep ilmu sosiologi yaitu interaksi sosial kehidupan masyarakat. Konsep ilmu ekonomi dipelajari melalui materi kehidupan perekonomian masyarakat pertanian. Konsep ilmu antropologi dipelajari melalui materi kehidupan masyarakat dalam kelembagaan budaya, kelembagaan sosial, dan kelembagaan agama. Terakhir, konsep ilmu geografi dipelajari melalui materi wilayah geografis tempat tinggal masyarakat.

\section{PEMBAHASAN}

\section{Kesenian Jaranan Turonggo Yakso dari Sudut Pandang IPS}

Berdasarkan hasil, Kesenian Jaranan Turonggo Yakso sebagai salah satu sumber belajar didalamnya terkandung sejumlah konsep-konsep keilmuan sosial. Turonggo Yakso mengajarkan khasanahnya melalui konsep ilmu geografi, ilmu sejarah, ilmu psikologi, ilmu ekonomi, ilmu sosiologi, ilmu antropologi, dan ilmu politik. Artinya, pengkajian atas sebuah kesenian budaya melalui konsep-konsep keilmuan akan dapat menguraikan potensi yang bermanfaat untuk belajar sesuatu.

Konsep ilmu sosial yang terkandung terbagi dalam tujuh konsep ilmu, yaitu (1) sejarah, Turonggo Yakso mengajarkan pengalaman hidup masyarakat berdasarkan kurun waktu masa lampau, (2) politik, mengajarkan usaha menegakkan norma dan nilai untuk mewujudkan kebaikan masyarakat, (3) psikologi, mengajarkan pemikiran dan tindakan masyarakat, (4) geografi, mengajarkan karakteristik wilayah dataran tinggi, (5) antropologi, mengajarkan cara hidup masyarakat Dongko dalam bersosial, berbudaya, dan beragama, (6) sosiologi, mengajarkan interaksi individu dan kelompok, (7) ekonomi, mengajarkan kegiatan produksi bahan baku pangan.

Penelitian terdahulu menyebutkan Tradisi Erau sebagai sumber belajar kontekstual memiliki kontribusi pada materi di bidang ilmu sosial seperti geografi, sejarah, sosiologi, ekonomi yang dapat diintegrasikan melalui pembelajaran (Khuriyah, 2013). Perbandingan dengan penelitian yang terdahulu memiliki kesamaan cara berkontribusi atas suatu objek sumber belajar yaitu berkontribusi melalui konsep bidang ilmu. Hal ini mengandung arti Kesenian Jaranan Turonggo Yakso sebagai salah satu sumber belajar kontekstual memiliki kontribusinya apabila dilihat dari sudut pandang konsep geografi, sejarah, psikologi, ekonomi, sosiologi, antropologi, dan politik.

\section{Kesesuaian Kesenian Jaranan Turonggo Yakso dengan Kompetensi Dasar IPS Kelas IV}

Berdasarkan hasil sejumlah konsep ilmu sosial yang terkandung dalam Kesenian Jaranan Turonggo Yakso sesuai dengan tema/topik yang akan diajarkan seperti "indahnya kebersamaan". Objek belajar dapat dimodifikasi sesuai tema yang akan diajarkan sehingga efektif sebagai salah satu sumber belajar (Prihastari, 2015). Turonggo Yakso sebagai salah satu sumber belajar sesuai dengan topik keragaman sosial, ekonomi, budaya, etnis, agama, dan karakteristik ruang. Seperti penelitian 
terdahulu tentang kesenian rebana yang sesuai untuk belajar dengan topik menghitung luas, selimut, volume, tinggi, jari-jari dan diameter (Putri, 2017). Penelitian lain yang serupa dengan penelitian ini menyebutkan suku Using melalui nilai-nilai yang dimilikinya cocok dengan kompetensi inti dan kompetensi dasar geografi pada junior high school (Musafiri et al., 2016). Nilainilai yang muncul pada kearifan lokal adat kampung naga cocok dengan kompetensi inti dan kompetensi dasar IPS kelas VII dan VIII (Qodariah \& Armiyati, 2015). Turonggo Yakso membawa rasa toleransi, persahabatan, sikap peduli sosial, sikap damai dan perasaan syukur yang dapat diadaptasi sehingga mampu menjadi sumber belajar IPS (Widyanto, Kurniadi, \& Wahida 2019a). Dari perbandingan hasil penelitian itu menunjukkan bahwa Turonggo Yakso bisa disesuaikan dengan tema/topik sesuai kepentingan belajar.

Hal ini mengandung arti bahwa Kesenian Jaranan Turonggo Yakso apabila dianalisis kepentingan belajarnya dengan benar maka akan terlihat bagian kesesuaiannya dengan materi yang akan diajarkan. Kesenian Jaranan Turonggo Yakso menjadi salah satu sumber belajar yang memiliki kesesuaian dengan materi IPS kelas IV.

\section{Peta Kompetensi Kesenian Jaranan Turonggo Yakso sebagai Sumber Belajar IPS}

Peta kompetensi menggambarkan bahwa Turonggo Yakso berkontribusi pada materi bidang sosiologi, ekonomi, budaya, dan geografi pada IPS kelas IV. Kontribusinya yaitu interaksi sosial kehidupan masyarakat, kehidupan perekonomian masyarakat, kehidupan masyarakat dalam kelembagaan budaya, kelembagaan sosial, dan kelembagaan agama, wilayah geografis tempat tinggal masyarakat. Artinya, peta kompetensi menggambarkan turunan kompetensi bidang ilmu untuk topik belajar yang akan diajarkan kepada peserta didik.

Penelitian terdahulu yang serupa menyebutkan bahwa Tradisi Erau sebagai sumber belajar kontekstual memiliki kontribusi dalam pembelajaran ilmu pengetahuan sosial berupa aspek sikap, pengetahuan, keterampilan, dan kontribusi pada materi bidang geografi, sejarah, sosiologi, dan ekonomi yang dapat diintegrasikan kepada pembelajaran (Khuriyah, 2013). Penelitian lain menyebutkan nilai budaya Masyarakat Kuta bermanfaat menjadikan pembelajaran IPS semakin bermakna dan peserta didik lebih termotivasi (Effendi, 2011). Kesenian Jaranan Turonggo Yakso dapat menjadi sumber belajar kontekstual yang bermakna bagi peserta didik dengan mempelajari budayanya sendiri. Hasil penelitian ini bermuara bahwa Kesenian Jaranan Turonggo Yakso dapat dijadikan sebagai salah satu sumber belajar IPS kelas IV.

Hal ini mengandung arti bahwa Kesenian Jaranan Turonggo Yakso mengandung khasanah ilmu dapat dijadikan sebagai sumber belajar IPS kelas IV. Sumber belajar yang disesuaikan dengan kepentingan belajar mampu mengontribusikan potensinya untuk belajar bagi peserta didik. Turonggo Yakso dapat menjadi salah satu sumber belajar kontekstual.

\section{SIMPULAN}

Kesenian Jaranan Turonggo Yakso salah satu sumber belajar yang memiliki khasanah keilmuan sosial seperti sosiologi, ekonomi, geografi, antropologi, psikologi, sejarah, dan politik. Ilmu sosial yang dikandung Kesenian Jaranan Turonggo Yakso dapat disesuaikan dengan topik kompetensi dasar IPS kelas IV dengan materi keragaman sosial, keragaman ekonomi, keragaman budaya, keragaman etnis, keragaman agama, dan karakteristik wilayah. Materi ilmu pengetahuan sosial yang didapatkan dari kontribusi Turonggo Yakso yaitu interaksi sosial kehidupan masyarakat, kehidupan perekonomian masyarakat pertanian, kehidupan manusia dalam kelembagaan budaya, sosial, agama, dan wilayah geografis tempat tinggal masyarakat.

Bagi akademisi perlu mengkaji Turonggo Yakso dari sudut pandang IPS agar memperoleh manfaat keilmuan sosial. Pendidik dapat mengintegrasikan sumber belajar kontekstual seperti Turonggo Yakso untuk meningkatkan proses pembelajaran. Diharapkan pendidik dapat menggunakan hasil penelitian ini sebagai acuan dalam menyiapkan sumber belajar.

\section{DAFTAR RUJUKAN}

Abdullah, R. (2012). Pembelajaran Berbasis Pemanfaatan Sumber Belajar. Jurnal Ilmiah Didaktika, 12(2), $216-231$. https://doi.org/10.22373/jid.v12i2.449

Alaz, N. Al, Suryani, N., \& Djono. (2018). A Needs Analysis of Historical Learning Model to Reinforce Student's Local Character using Local Wisdom Values of Turonggo Yakso Art. VNU Journal of Science: Education Research, 34(4), 1-7. https://doi.org/10.25073/2588-1159/vnuer.4163

Easton, K. L., McComish, J. F., \& Greenberg, R. (2000). Avoiding Common Pitfalls in Qualitative Data Collection and Transcription. Qualitative Health Research, 10(5), 703-707. https://doi.org/10.1177/104973200129118651

Effendi, S. A. (2011). Implementasi Kearifan Lingkungan Dalam Budaya Masyarakat Adat Kampung Kuta sebagai Sumber Pembelajaran IPS. Sosio Didaktika, 1(2), 211-218.

Gill, P., Stewart, K., Treasure, E., \& Chadwick, B. (2008). Methods of Data Collection in Qualitative Research: Interviews and Focus Groups. British Dental Journal, 204(6), 291-295. https://doi.org/10.1038/bdj.2008.192

Glynn, S. M., \& Winter, L. K. (2004). Contextual Teaching and Learning of Science in Elementary Schools. Journal of Elementary Science Education, 16(2), 51-63. https://doi.org/10.1007/BF03173645

Hvitfeldt, C. (1986). Traditional Culture, Perceptual Style, and Learning: The Classroom Behavior of among Adults. Adult Education Quarterly, 36(2), 65-77. https://doi.org/10.1177/0001848186036002001 
Irianto, A. M. (2017). Kesenian Tradisional sebagai Sarana Strategi Kebudayaan di Tengah Determinasi Teknologi Komunikasi. Nusa: Jurnal Ilmu Bahasa dan Sastra, 12(1), 90. https://doi.org/10.14710/nusa.12.1.90-100

Khuriyah, L. (2013). Kontribusi Tradisi Erau sebagai Sumber Pembelajaran Kontekstual IPS. Journal of Chemical Information and Modeling, 53(9), 1689-1699. https://doi.org/10.1017/CBO9781107415324.004

Lee, B., \& Cawthon, S. (2015). What Predicts Pre-Service Teacher Use of Arts-Based Pedagogies in the Classroom? An Analysis of the Beliefs, Values, and Attitudes of Pre-Service Teachers. Journal for Learning through the Arts, 11(1), 115.

Moleong, I. J. (2013). Metodologi Penelitian Kualitatif. Bandung: Remaja Rosdakarya.

Musafiri, R., Utaya, S., \& Astina, I. K. (2016). Potensi Kearifan Lokal Suku Using sebagai Sumber Belajar Geografi SMA di Kabupaten Banyuwangi. Jurnal Pendidikan: Teori, Penelitian, dan Pengembangan, 1(10), 2040-2046.

Nelson, J. (2001). Defining Social Studies. Critical Issues in Social Studies Research for the 21 ${ }^{\text {st }}$ Century, 1, 15-38.

Perkasa, M. C., \& Prasetyo, A. (2018). Turonggo Yakso Dalam Etnofotografi. Capture: Jurnal Seni Media Rekam, 9(2), 1. https://doi.org/10.33153/capture.v9i2.2063

Polkinghorne, D. E. (2005). Language and Meaning: Data Collection in Qualitative Research. Journal of Counseling Psychology, 52(2), 137-145. https://doi.org/10.1037/0022-0167.52.2.137

Prihastari, E. B. (2015). Pemanfaatan Etnomatematika melalui Permainan Engklek sebagai Sumber Belajar. Mendidik: Jurnal Kajian Pendidikan dan Pengajaran, 1(2), 155-162.

Putri, L. I. (2017). Eksplorasi Etnomatematika Kesenian Rebana sebagai Sumber Belajar Matematika pada Jenjang MI. Jurnal Ilmiah Pendidikan Dasar, 4(1), 21-31.

Qodariah, L., \& Armiyati, L. (2015). Nilai-Nilai Kearifan Lokal Masyarakat Adat Kampung Naga sebagai Alternatif Sumber Belajar. SOCIA: Jurnal Ilmu-Ilmu Sosial, 10(1), 10-20. https://doi.org/10.21831/socia.v10i1.5338

Sears, S. (2003). Introduction to Contextual Teaching and Learning (Donovan R.). Phi Delta Kappa Educational.

Surur, M. (2013). Turonggo Yakso Berjuang untuk Sebuah Eksistensi. Dinas Kebudayaan dan Pariwisata.

Tryon, R. M. (1983). Teaching the Social Studies: Theory and Practice. Edgar Bruce Wesley. The Elementary School Journal, 38(8), 630-631. https://doi.org/10.1086/462236

Whitbeck, L. B., Hoyt, D. R., Stubben, J. D., Lafromboise, T., Whitbeck, L. B., Hoyt, D. R., Stubben, J. D., \& Lafromboise, T. (2020). Traditional Culture and Academic Success among American Indian Children in the Upper Midwest Over the past. 40(2), 48-60.

Widyanto, A., Kurniadi, E., \& Wahida, A. (2019a). Shape And Meaning of Head at Property of Jaranan Turonggo Yakso. International Journal of Advanced Multidisciplinary Scientific Research, 2(2), 13-28. https://doi.org/10.31426/ijamsr.2019.2.2.1212

Widyanto, A., Kurniadi, E., \& Wahida, A. (2019b). The Analysis of Design and Meaning on Jaranan Turonggo Yakso Art and Its Relevance toward Character Education. 279(Icalc 2018), 9-14. https://doi.org/10.2991/icalc-18.2019.2

Wisang, A. M. (2019). Cultural Co-Modification of Jaranan Turangga Yakso Dance in Jaranan Festival Intrenggalek Region. Journal of Advances in Social Science and Humanities, 5(1), 555-561. https://doi.org/10.15520/jassh51394 